\title{
A EDUCAÇÃO EMPREENDEDORA APOIADA POR METODOLOGIAS ATIVAS DE ENSINO - UM ESTUDO DE CASO
}

DOI: 10.37702/2175-957X.COBENGE.2021.3660

Ercilia de Stefano - ercilia.stefano@gmail.com

UFF

Rua Antônio Da Silva Ligeiro 207

25645-250 - Petrópolis - RJ

Alexia Seixas de Oliveira - alexiaseixas@id.uff.br

Universidade Federal Fluminense

Rua Alvares de Azevedo 865

25730-020 - Petrópolis - RJ

Talita Kronenberger de Almeida - talitakronenberger@id.uff.br Universidade Federal Fluminense

Av Gal Marciano Magalhães 1097

25630-025 - Petrópolis - RJ

Hannah Carolina Reis De Castro - hannahcarolina@id.uff.br

Universidade Federal Fluminense

R.Dom.Silvério,1 135

25650-050 - Petrópolis - RJ

Resumo: Resumo: Afim de compreender os efeitos causados pela utilização das metodologias ativas de ensino e da educação empreendedora como métodos de aprendizagem inovadores em algumas disciplinas do curso de Engenharia de Produção da Universidade Federal Fluminense, em Petrópolis, foram analisados o desempenho dos alunos e o seu perfil após a conclusão de cinco disciplinas. Constatou-se, portanto, a influência direta nos alunos quando se percebe a elevação do desempenho nas disciplinas, agilidade para buscar informação, espírito empreendedor e maior interesse por tecnologia e inovação.

Palavras-chave: Educação, Metodologias ativas, Inovação, Tecnologia, Alunos 


\section{A EDUCAÇÃO EMPREENDEDORA APOIADA POR METODOLOGIAS ATIVAS DE ENSINO - UM ESTUDO DE CASO}

\section{INTRODUÇÃO}

No Brasil, a maioria de nossos empreendedores o fazem por necessidade, o que resulta, infelizmente em uma alta taxa de insucesso. Isso evidencia a importância e a necessidade da Educação Empreendedora, para que durante a formação do indivíduo, ele tenha acesso às teorias e a oportunidades de praticar os conhecimentos aprendidos. A educação empreendedora traz profissionalismo a criação de novos negócios, igualando em conhecimento os jovens brasileiros, oportunizando a explorarem suas habilidades para empreender, além de formar alunos proativos, interessados, inovadores e autônomos.

A escola padronizada, que ensina e avalia a todos da mesma forma e exige resultados previsíveis, ignora que a sociedade do conhecimento é baseada em competências cognitivas, pessoais e sociais, que não se adquirem da forma convencional, e que exigem proatividade, colaboração, personalização e visão empreendedora (MORÁN, 2015). As metodologias ativas de ensino contrapõem o estudo tradicional fazendo com que o aluno seja o protagonista do processo de aprendizagem, promovendo interação e trabalho em equipe além de fomento à inovação. A importância de tais ferramentas evidenciam-se por terem sido incorporadas às novas DCNs (Diretrizes Curriculares Nacionais) de Engenharia, que trazem a necessidade de mudança na forma de ensino adequando-se às novas tecnologias, tornando-a mais abrangente e eficaz.

\section{REFERENCIAL TEÓRICO}

\subsection{Educação Empreendedora}

Diante do contexto brasileiro de grandes dificuldades econômicas, a prática do empreendedorismo muitas vezes é vista como uma forma de profissão alternativa, ou para momentos de desemprego. Assim, a introdução do empreendedorismo no ensino pode trazer um grande diferencial para aqueles que buscam empreender, podendo garantir-Ihes uma maior segurança ao começar um novo negócio.

Atualmente, a partir dos estudos acerca do tema empreendedorismo, verifica-se que o empreendedor não pode ser apenas entendido como a pessoa que nasce com vocação para empreender, mas como uma pessoa que possuí um conjunto de características que levam a pessoa a ser empreendedor, e, estas características podem ser desenvolvidas em qualquer pessoa (TAVARES, MOURA, ALVES, 2013). Com isso, a educação empreendedora se mostra conveniente, além de necessária para estimular as pessoas a serem inovadoras e empreendedoras.

A origem da educação empreendedora no Brasil teve início nos cursos de administração, sendo que o primeiro curso surgiu em 1981, pela Fundação Getúlio Vargas, na especialização em Administração para graduados, com a disciplina de Novos Negócios. Pelo sucesso e interesse dos alunos, surgiram outras como: Criação de Novos NegóciosFormação de empreendedores, Criação de Empresas, Criação de Empresas e Empreendimentos de Base Tecnológica e Empreendedorismo, as quais também foram através de cursos de Administração, com algumas delas sendo por meio de outras instituições. 
Pode-se perceber que a educação empreendedora pode focar na formação do indivíduo ou focar naquele que se interessa por uma oportunidade, e que estaria em uma fase anterior à criação de um negócio; pode, ainda, voltar-se para os que já estariam na fase de criação de um empreendimento e, até mesmo, para aqueles que estão em fases posteriores à criação e que estão preocupados com as estratégias para permanecer ativo ou expandir o negócio. (LOPES, 2012, p. 25).

Em cursos de Engenharia que existem disciplinas de empreendedorismo, ela visa introduzir o conhecimento, e em alguns cursos, não apenas pela exposição de conteúdo, mas através da prática. São apresentadas ferramentas de gestão empresarial e estimulam o aluno a obter um maior interesse pelo mundo dos negócios, além de proporcioná-lo uma visão empreendedora.

Figura 1: Características e elementos envolvidos na educação empreendedora CARACTERÍSTICAS DA EDUCAÇÃO EMPREENDEDORA

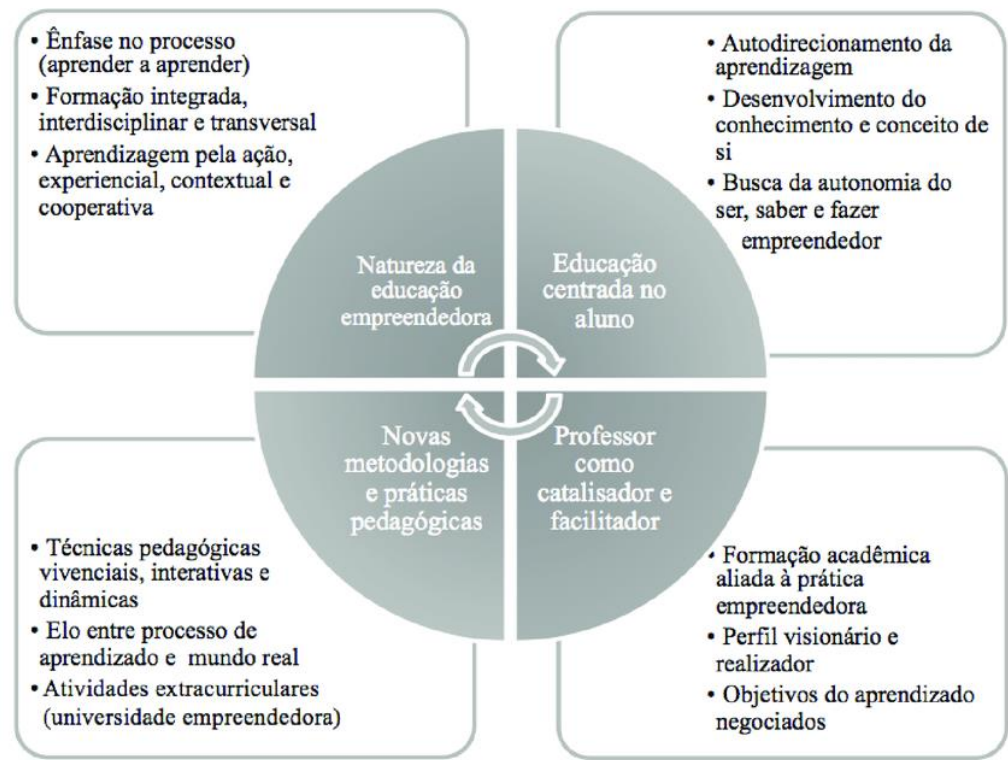

Fonte: Schaefer e Minello (2015)

\subsection{Novas Diretrizes Curriculares Nacionais de Engenharia}

Devido a carência de engenheiros qualificados para introduzir melhorias e aumentar a produtividade das indústrias que constantemente vão sofrendo modificações em espaços de tempo cada vez menores, as Novas Diretrizes Curriculares, estabelecidas pela Câmara de Educação Superior do Conselho Nacional de Educação (CES/CNE), propõem experiências práticas e ativas de aprendizagem em conjunto com conhecimentos diferenciados, que desenvolvem no estudante a capacidade de resolução de problemas numa perspectiva multidisciplinar e afloram o seu pensamento crítico. Tal desempenho surge da prática de atividades como: Estudo individual e em grupo, consulta a fontes bibliográficas e a recursos de informática, desenvolvimento de projetos, debates. etc.

É interessante e de extrema importância que haja uma comunicação entre a instituição acadêmica e o mercado de trabalho para a habituação do egresso e também para dinamizar o ensino e promover a inovação das empresas no âmbito tecnológico.

Sendo assim, no capítulo II que se trata do perfil e competências esperadas do egresso, destaque para os artigos $3^{\circ}$ e $4^{\circ}$, e do capítulo III, destaque para o artigo 6ํㅡㄴ das novas DCNs, (ABMES, 2019) pode-se observar o que deve compreender o perfil exigido para a engenharia. 
As novas DCNs dizem sobre a educação empreendedora que as competências e habilidades empreendedoras são exigências das empresas contemporâneas e da sociedade de economia impulsionada pela inovação por perfil de engenheiros que promova inovação incremental ou radical, que desenhe e implemente estruturas inovadoras e empreendedoras (GIBB, 2002).

A educação empreendedora é um fator de influência novo perfil do egresso em engenharia e um desafio estabelecido nas novas DCNs. Entretanto, ela promove a abertura de diversas lacunas, tensões e formulação de questões nas IES.

A educação empreendedora como um eixo norteador da formação do profissional de acordo com as novas DCNs, com o propósito de levar o aluno a abrir novas empresas e/ou fomentar competências empreendedoras para que o egresso possa atuar em qualquer ambiente de trabalho, seja em empresas existentes ou novas empresas, setores governamentais e organizações em geral.

\subsection{Metodologias Ativas de Ensino}

Um provérbio chinês de Confúcio diz sabiamente "O que eu ouço, eu esqueço; o que eu vejo, eu lembro; o que eu faço, eu compreendo". Sua citação é contextualizada com o entendimento das metodologias ativas, e Silberman (1996) modificou esse provérbio, conforme descrito a seguir: que eu ouço, eu esqueço; o que eu ouço e vejo, eu me lembro; o que eu ouço, vejo e pergunto ou discuto, eu começo a compreender; o que eu ouço, vejo, discuto e faço, eu aprendo desenvolvendo conhecimento e habilidade; o que eu ensino para alguém, eu domino com maestria.

A descrição resume com propriedade os princípios das metodologias ativas de ensino. De acordo com Pereira (2012) podemos entender por Metodologia Ativa todo o processo de organização da aprendizagem cuja centralidade do processo esteja, de forma efetiva, no estudante. Marin et al. (2010) apontam como os principais pontos positivos da utilização de metodologias ativas a aproximação da realidade; a integração entre a teoria e a prática; a preparação para o trabalho em grupo; e, com destaque, aluno como responsável pela sua aprendizagem.

Sendo assim, a aprendizagem ativa ocorre quando o aluno interage com o assunto em estudo, sendo estimulado a construir o conhecimento, ao invés de recebê-lo de forma passiva do professor. Na forma ativa de ensino o professor atua como facilitador do processo de aprendizagem, ao invés de fonte única de informação e conhecimento. Para efetiva aplicação da metodologia ativa é necessário, independentemente do método escolhido, que o aluno esteja engajado e faça uso de suas funções de pensar, raciocinar, entre outras, que formam, em conjunto, a inteligência (Pecotche, 2011).

A figura 2 a seguir ilustra os pontos basilares das metodologias ativas de ensino, melhor descrita a seguir.

Figura 2: Pontos basilares das metodologias ativas de ensino 


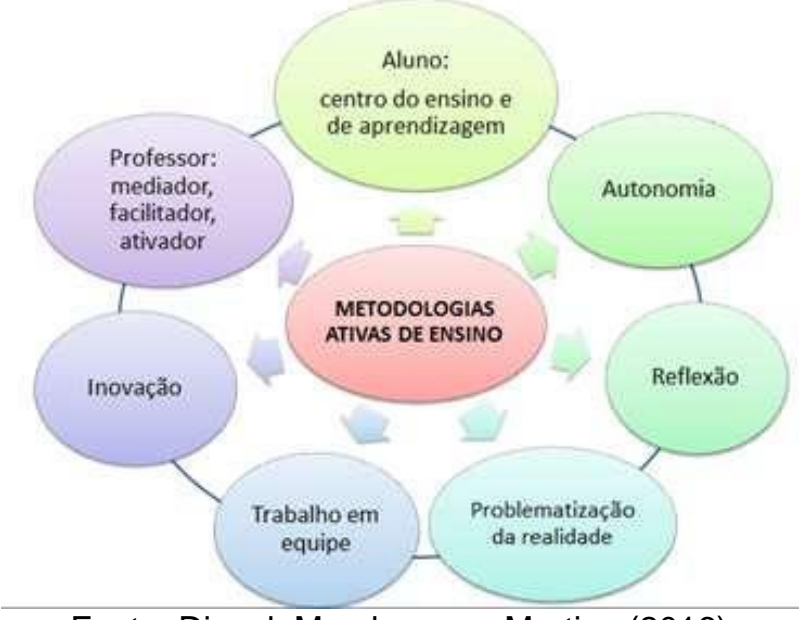

Fonte: Diesel, Marchesan e Martins (2016)

Observa-se que aprendizagem ativa se refere a estratégias para envolver o aluno e motivar a autoaprendizagem, sendo o aluno o sujeito ativo responsável por sua construção do conhecimento. O professor, no modelo tradicional de ensino, se encontrava em uma posição ativa ao ensinar de forma unilateral, neste modelo é um mediador, facilitador, e encontra-se agora em uma posição passiva.

Moran (2015) afirma que "Quanto mais aprendamos próximos da vida, melhor. As metodologias ativas são pontos de partida para alavancar processos mais avançados de reflexão, de integração cognitiva, de generalização, de reelaboração de novas práticas".

De acordo com Glasser (2010) "A boa educação é aquela em que o professor pede para que seus alunos pensem e se dediquem a promover um diálogo para promover a compreensão e o crescimento dos estudantes". A figura 3, a seguir, traz a Pirâmide de Glasser, que explicita claramente as formas de autoconstrução do conhecimento.

Figura 3: Pirâmide de Aprendizagem de Glasser

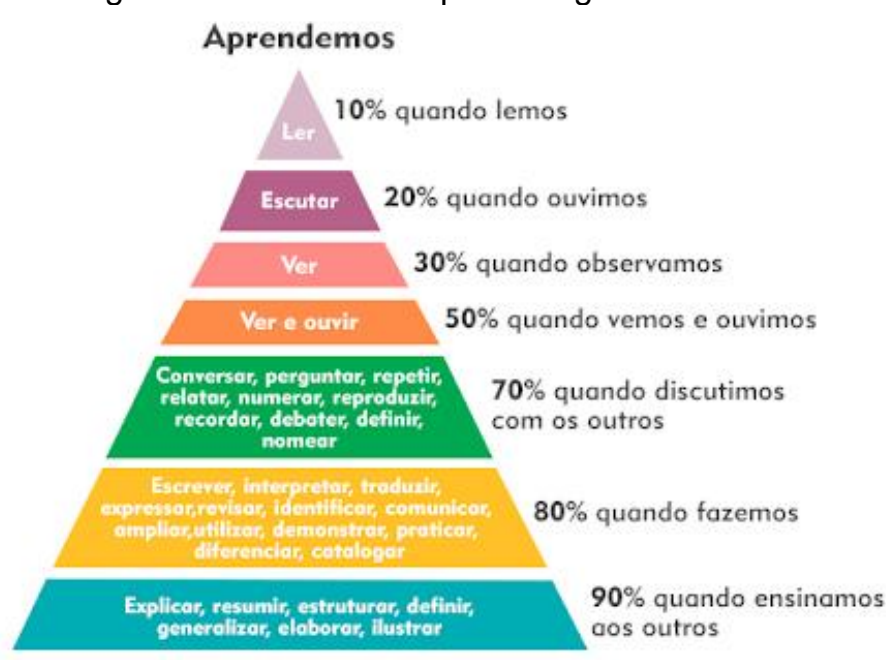

Fonte: Glasser (2010)

É possível observar que ao serem mais ativos, os alunos passam a aumentar gradativamente a porcentagem de conteúdo retido, corroborando a pirâmide, sendo a mesma o alicerce da importância da utilização das metodologias ativas de ensino.

Paulo Freire (1996) defende as metodologias ativas afirmando que na educação de adultos, o que impulsiona a aprendizagem é a superação de desafios, a resolução de problemas e a construção do conhecimento novo a partir de conhecimentos e experiências 
prévias dos indivíduos, fundamentos esses que são aplicáveis a estudantes de todas as faixas etárias.

Fica claro que os alunos, como sujeitos ativos da criação do seu saber, são empreendedores de seu próprio futuro, na construção de seu conhecimento, na construção de sua carreira profissional, e empreendedor nas mudanças necessárias para que obtenha êxito em seu plano de negócios pessoal.

\subsection{O empreendedorismo no Ensino Superior}

Dolabela (2008) menciona a forte relação entre as universidades com o tema empreendedorismo:

"[...] a universidade deve provocar o autoconhecimento, fazer o aluno descobrir o seu sonho. Se você não vai atrás de seu sonho, não concebe seu futuro. [...]". A produção repetitiva perde espaço para quem inova. O que vale é a capacidade das pessoas de mudar. Foi um jovem rebelde que criou o Google."

O autor enfatiza é que as universidades precisam aproveitar-se do entusiasmo que possuem os jovens para provocar o autoconhecimento, motivá-los para que estes descubram seus sonhos, e também contribuir para despertar as características do empreendedor. Nessa abordagem o ensino tradicional perde seu espaço, e não dá espaço para a educação empreendedora.

Percebe-se que a educação empreendedora tem forte relação com a necessidade de se estimular o protagonismo dos alunos. Tanto o protagonismo quanto o perfil empreendedor são assimilados com a utilização da abordagem baseada em metodologias ativas de ensino.

Alguns exemplos de metodologias ativas: aprendizagem baseada em equipe (TBL Team Based Learning), gameficação, aprendizagem entre pares, discussões em grupo, estudos de caso, sala de aula invertida, aprendizagem colaborativa, aprendizagem baseada em problemas (PBL - Problem Based Learning), aprendizagem baseada em projetos, dentre outras. Na sequência apresenta-se os conceitos de três das mencionadas metodologias, por estarem relacionados ao estudo de caso apresentado no tópico 3 do presente artigo.

\subsection{Team-Based Learning (TBL)}

A Aprendizagem Baseada em Times (Team-Based Learning - TBL) consiste em uma estratégia educacional baseada em um conjunto de práticas sequenciadas de ensinoaprendizagem visando promover o desenvolvimento de equipes de alto desempenho e fornecer a estas a oportunidades de se envolver em tarefas de aprendizagem significativas. Como a metodologia requer que as atividades possuam conexão entre sua utilização, geralmente, exige reestruturação do curso ou disciplina, na qual será utilizada. Ainda assim, quando a transformação do curso não é possível, sua utilização mais pontual também surte efeitos pedagógicos. (OLIVEIRA et. al, 2018)

A aprendizagem baseada em times foi criada pelo professor de gestão e negócios Larry Michaelsen (MICHAELSEN, KNIGHT; FINK, 2004) no final dos anos 70, na universidade de Oklahoma (EUA). O método tem como foco melhorar a aprendizagem e desenvolver habilidades de trabalho colaborativo, através de uma estrutura que envolve: 0 gerenciamento de equipes de aprendizagem, tarefas de preparação e aplicação de conceitos, feedback constante e avaliação entre os colegas. A ideia central é que os alunos se sintam responsáveis pela própria aprendizagem e pela dos colegas.

No TBL cada tema principal a ser trabalhado em um módulo requer três etapas que são o preparo, a garantia do preparo e a aplicação dos conceitos, etapas essas que podem 
ser observadas na figura a seguir (figura 4). O método proporciona um ambiente motivador e co-operativo, o que ajuda a minimizar o desinteresse dos estudantes pelo tema da aula, tornando-os responsáveis pela própria aprendizagem e pela dos colegas.

Figura 4: Etapas do TBL e sua duração aproximada

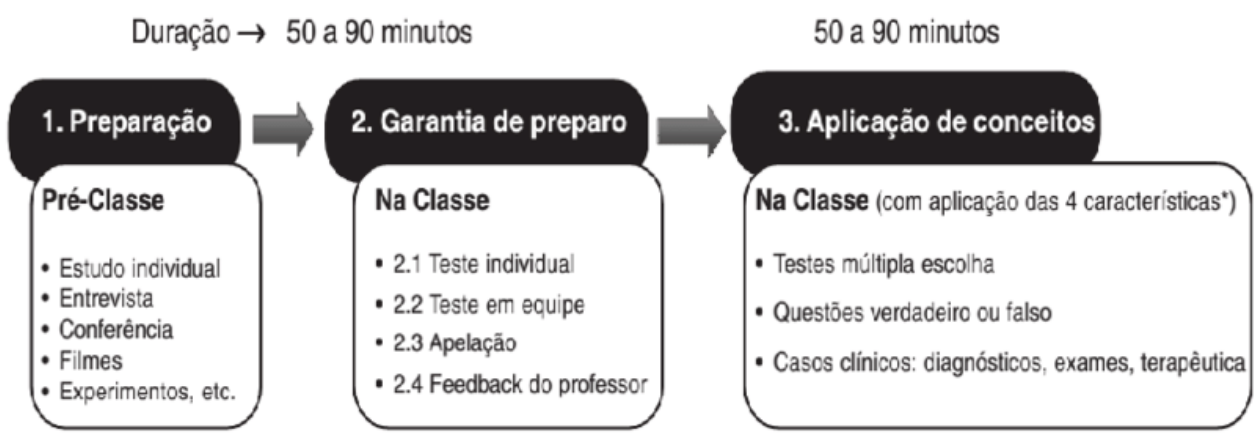

Fonte: Bolella et al. (2014)

Segundo Michaelsen, Watson e Black (1989), foi demonstrado que, em $98 \%$ dos casos, o desempenho da equipe supera o melhor desempenho individual dos seus membros. O que nos leva aos quatro elementos essenciais para o sucesso da aplicação da metodologia segundo Michaelsen, Sweet e Parmelee (2008):

a) Grupos: Os grupos devem ser bem formados e gerenciados adequadamente;

b) Responsabilidade: os alunos devem ser responsáveis pela qualidade de seu trabalho individual e em grupo;

c) Feedback: Os estudantes devem receber feedback continuamente;

d) Designação de tarefas: As tarefas do grupo devem promover tanto aprendizado quanto desenvolvimento para a equipe.

Estes quatro princípios determinam o sucesso deste método, segundo os autores supracitados. É importante considerar que uma vez formadas as equipes, elas devem manter-se inalteradas até o final do módulo ou curso pois foi observado que ao longo das aplicações da metodologia as equipes se tornam mais coesas, facilitando os debates.

O TBL propõe várias atividades onde os estudantes podem ser avaliados de forma somativa e formativa, ao contrário da sala de aula tradicional que promove diversas avaliações somativas com o conteúdo total do semestre, onde geram pontos para os alunos. A partir desta forma de avaliação, o TBL instiga os alunos a responsabilização pelo estudo prévio, e da equipe, pela sua contribuição. Caso não o ocorra o preparo prévio, eles acabam por prejudicar a si mesmos e a sua equipe. Michaelsen, Sweet e Parmelee (2008) sugerem que os estudantes levem em consideração: o estudo antecipado; a participação nas atividades em equipe; o respeito ao ouvir opiniões diversas; a flexibilidade para lidar com possíveis conflitos; promover feedback para a equipe.

A metodologia TBL encontra-se alinhada com as novas DCNs para os cursos de Engenharia (BRASIL, 2019). O Ministério da Educação (MEC) menciona que o trabalho em equipe deve ser uma exigência para uma educação transformadora. Assim, a colaboração dos estudantes em grupo por meio da metodologia TBL é determinante para o sucesso da equipe.

\subsection{Gamificação}


Segundo Karl Kapp (2012), gamificação é "o uso das mecânicas, estéticas e pensamentos dos games para envolver pessoas, motivar a ação, promover a aprendizagem e resolver problemas".

Atualmente essa metodologia surge como uma possibilidade de conectar a escola ao universo dos jovens, estes que carregam diversos aprendizados advindos dos games, com o foco na aprendizagem, por meio de práticas como sistemas de rankeamento e fornecimento de recompensas. Mas, ao invés de focar nos efeitos tradicionais como notas, por exemplo, utilizam-se estes elementos alinhados com a mecânica dos jogos para promover experiências que envolvem emocionalmente e cognitivamente os alunos, devido ao fato de ser uma área que necessita de novas estratégias para estimular os estudantes, que estão cada dia mais inseridos no mundo da tecnologia, se mostrando desinteressados pelos atuais métodos utilizados pelas escolas. Para Fardo (2013):

"A gamificação pode promover a aprendizagem porque muitos de seus elementos são baseados em técnicas que os designers instrucionais e professores vêm usando há muito tempo. Características como distribuir pontuações para as atividades, apresentar feedback e encorajar a colaboração em projetos são as metas de muitos planos pedagógicos. A diferença é que a gamificação provê uma camada mais explícita de interesse e um método para costurar esses elementos de forma a alcançar a similaridade com os games, o que resulta em uma linguagem a qual os indivíduos inseridos na cultura digital estão mais acostumados e, como resultado, conseguem alcançar essas metas de forma aparentemente mais eficiente e agradável."

Ainda de acordo com Fardo (2013), para aplicar esta metodologia para transformação do ensino e da aprendizagem, algumas linhas gerais podem ser tomadas como ponto de partida. Dessa forma, os seguintes apontamentos são considerados: disponibilizar diferentes experimentações; incluir ciclos rápidos de feedback; aumentar a dificuldade das tarefas conforme a habilidade dos alunos; dividir tarefas complexas em outras menores; incluir o erro como parte do processo de aprendizagem; incorporar a narrativa como contexto dos objetivos; promover a competição e a colaboração nos projetos; levar em conta a diversão.

Os jogos foram reconhecidos pelo Ministério da Cultura como um produto audiovisual, e ambientes gamificados receberam apoio do Ministério da Educação, tendo como exemplo a plataforma online Geekgames, que se trata de uma plataforma de aprendizado adaptativo para estudantes em preparação para o Exame Nacional do Ensino Médio (ENEM), através de desafios. É possibilitado aos alunos inscritos identificar suas limitações e ter acesso a um estudo personalizado que permite avanços nas áreas a serem avaliadas pelo ENEM. (ALVES, MINHO e DINIZ, 2014)

Perante os resultados positivos atribuídos ao uso do Geekgames o MEC estudou a possibilidade de gamificar a avaliação do Programa Internacional de Avaliação de Estudantes (PISA), que mede a habilidade de estudantes de 15 anos em matemática, leitura e ciências, e também, a Prova Brasil, exame realizado com alunos de $5^{\circ}$ e $9^{\circ}$ anos do ensino fundamental e $3^{\circ}$ ano do ensino médio de escolas públicas brasileiras. (ALVES, MINHO e DINIZ, 2014)

A gameficação alinhada com a metodologia TBL permite fazer as verificações de forma mais atrativa, lúdica e instigante para os alunos.

\subsection{Sala de aula invertida}


A ideia da sala de aula invertida foi criada por Lage, Platt e Treglia (1996), conhecida como "inverted classroom" e usada pela primeira vez em uma disciplina de Microeconomia em 1996 na Miami University (Ohio, EUA).

A partir dos anos 2010, passou-se a usar o termo "flipped classroom" por conta de publicações no The New York Times (FITZPATRICK, 2012), no Chronicle of Higher Education (BERRETT, 2012). Desde então surgiram diversos exemplos de escolas e Instituições de Ensino Superior adotando esta metodologia.

A figura 5 ilustra as principais diferenças entre a sala de aula tradicional e a aula invertida, que apresenta características comuns a metodologia baseada em times.

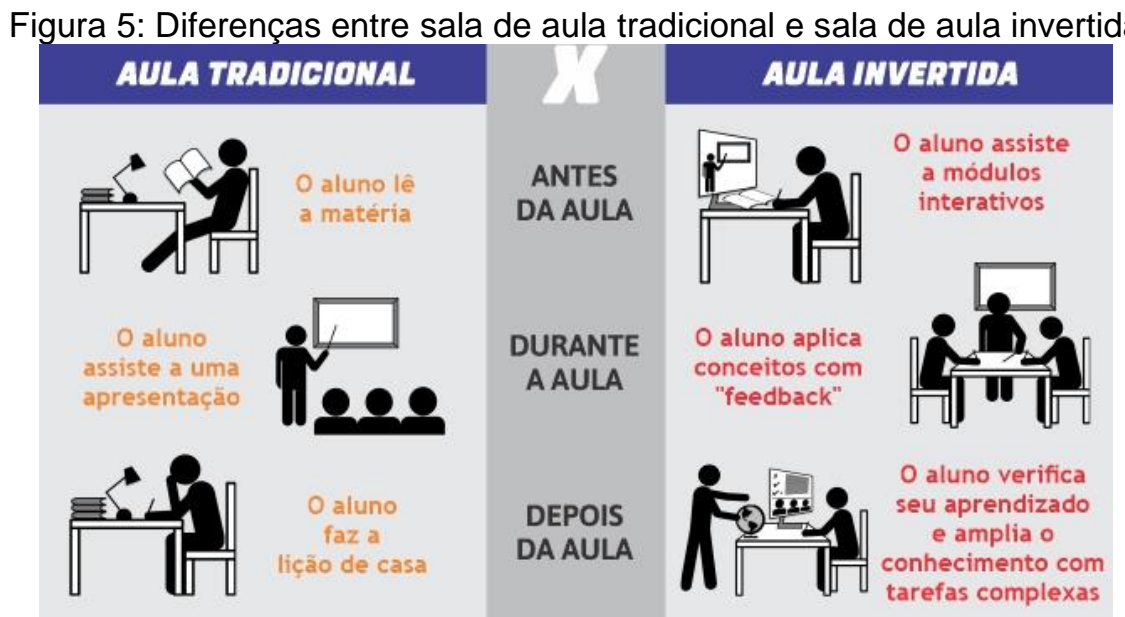

Fonte: Alcides Yukie Horie (2019)

Conforme apresentado na figura 5, as atividades educacionais são invertidas ou seja, o que costuma-se ser feito em sala de aula passa a ser realizado como trabalho de casa, por exemplo, ao invés dos alunos assistirem uma aula expositiva sobre as políticas públicas e em seguida irem para casa tendo uma atividade como artigo ou resenha do assunto, no Flipped Classroom os discentes consultam materiais realizando pesquisas prévias sobre o assunto antes da aula e, em seguida, envolvem-se em estratégias de aprendizagem ativa, como os debates sobre questões pertinentes durante a aula (GILBOY; HEINERICHS; PAZZAGLIA, 2015).

Algumas atividades em sala podem ser mais estruturadas, como a "flipped mastery" proposta por Bergmann e Sams (2012) que consiste em um modelo no qual os alunos avançam para novos objetivos somente após terminar os anteriores. Também podem ser mais desafiadoras, como propostas por Driscoll (2014) utilizando os conceitos de jogos e assim transformar as avaliações em missões nas quais os estudantes conquistam pontos a de acordo com seu progresso.

É sabido que a percepção dos discentes provenientes do ambiente de aprendizagem de Flipped Classroom é melhor do que a aula tradicional, o que sugere a sala de aula de aprendizagem ativa sendo um uso mais eficiente do espaço físico (BAEPLER; WALKER; DRIESSEN, 2014), onde os alunos são empreendedores do seu próprio conhecimento.

A experiência de Baepler, Walker e Driessen (2014) demonstrou que os alunos alcançaram resultados de aprendizagem significativamente melhores em comparação com os alunos em uma sala de aula tradicional. Deve-se levar em consideração que o engajamento do aluno em estudos prévios em casa pode afetar a satisfação dos mesmos, mostrado no experimento de Missildine et al. (2013) onde se observou uma maior satisfação dos participantes quanto a utilização da Flipped Classroom em conjunto a outras atividades inovadoras de ensino. 
Com o surgimento da pandemia e a necessidade das aulas no formato remoto, atendendo as exigências de isolamento social, é preciso que a educação se adapte às novas tecnologias, e as metodologias ativas de ensino têm se mostrado como grande diferencial e motivador para os alunos neste novo modelo de ensino, que teve que ser reinventar para atender às atuais demandas, conforme descrito a seguir.

\section{ESTUDO DE CASO}

O estudo de caso apresentado a seguir é referente a três períodos letivos, tendo início em 2019. Compreende a aplicação das metodologias ativas: TBL, sala de aula invertida e gameficação, sendo essas associadas a avaliação formativa e continuada. As metodologias vêm sendo empregadas pela Professora Ercilia de Stefano, no curso de Engenharia de Produção, na UFF Petrópolis, nas disciplinas de Gestão de Projetos, Gestão de Projetos de Sistemas de Produção, Empreendedorismo I, Empreendedorismo II e Gestão da Inovação Tecnológica, as quais leciona.

Por semestre, as cinco disciplinas totalizam em média cerca de 150 alunos. 0 semestre atual é o terceiro período letivo onde as metodologias estão sendo aplicadas.

As aulas são construídas dinamicamente, conforme descrito a seguir:

a) Os alunos recebem na primeira aula do semestre o tema que será abordado em cada aula. A divisão dos temas contempla toda a ementa de cada disciplina, o que possibilita ministrar todo o conteúdo atribuído;

b) Na primeira aula os alunos são apresentados às metodologias ativas que serão utilizadas no período, e também são apresentados à Pirâmide de Glasser, onde é explicitado os princípios da construção do conhecimento, a plasticidade mental e a efetividade de cada uma delas na fixação do conteúdo, deixado claro que o aluno é empreendedor na construção de seu conhecimento e futuro como engenheiro;

c) Antes de cada aula, individualmente, os alunos devem pesquisar e estudar sobre o tema proposto, característica essa que faz parte das metodologias ativas de ensino TBL e sala de aula invertida;

d) Utilizando os princípios das referidas metodologias ativas, no dia da aula, os 50 minutos iniciais são destinados para que os alunos, em grupos de no máximo seis alunos, debatam e discutam entre si os conhecimentos individualmente aprendidos. Os alunos escolhem seus próprios grupos, pois a afinidade entre os pares é muito importante para o sucesso do aprendizado. Os grupos são mantidos por todo o semestre;

e) Nos 50 minutos subsequentes é realizado um debate com todos os alunos da turma, dispondo as carteiras em um grande círculo (nas aulas presenciais), onde o tema da aula é apresentado pelos próprios alunos, onde atuo como mediadora. Nas aulas remotas os debates acontecem pela plataforma adotada pela Universidade para a realização das aulas síncronas;

f) Após o encerramento da aula, uma questão de fixação é proposta, para que os alunos respondam individualmente. A questão faz parte da avaliação continuada e formativa da disciplina, e vale parte da nota da AV1 (avaliação 1 - na UFF são obrigatórias duas avaliações por semestre). Nas aulas presenciais, um aplicativo foi utilizado, em algumas turmas, apresentando questões no formato de quiz, com suporte de um aplicativo de marca proprietária;

g) No final do semestre é realizado um trabalho em grupo, que pode ser um artigo científico, um plano de negócios ou um projeto, dependendo da disciplina. Antes do período da pandemia, os alunos realizaram projetos e planos de negócios para ONGs, microempreendedores e pequenos comerciantes, de forma não onerosa, colocando em prática os conhecimentos apreendidos nas aulas. 
Vale destacar que nos últimos 10 meses foram publicados em parceria com alunos e professores 14 trabalhos científicos, entre artigos completos e capítulos de livros.

Como resultado da utilização das metodologias ativas e avaliação continuada, foi observado:

a) Nos 3 semestres analisados, houve 100\% de aprovação, com nota média de 8,9 (de 10 pontos), não havendo nenhum aluno realizado avaliação final (recuperação);

b) Aprimoramento da oratória, das técnicas de apresentação em público, da comunicação entre pares e do trabalho colaborativo, em times;

c) Os alunos são empoderados pela autoconstrução do conhecimento, algo extremamente importante no futuro da carreira. As tecnologias avançam em uma velocidade exponencial, e a atualização profissional tem que ser rápida e constante, para acompanhar o mercado;

d) Mudança na postura dos alunos. Passar a ser proativos, assertivos e o empreendedores, tendo alguns alunos criado seus próprios negócios;

e) Ampliação do senso crítico, formando engenheiros autônomos, preparados para o mercado globalizado, para os desafios da Indústria 4.0 e para a sociedade em que vivemos;

f) Alunos assíduos, motivados e participativos nas aulas;

g) Conceitos como Sustentabilidade, Economia Circular, Empreendedorismo Social, Indústria 4.0, Sociedade 5.0, Inteligência Artificial e Internet das Coisas (IoT), são abordados ao longo das disciplinas, utilizando pesquisas recentes e estudos de caso.

\section{CONSIDERAÇÕES FINAIS}

As Novas Diretrizes Curriculares Nacionais de Engenharia incluem a utilização das metodologias ativas de ensino como forma importante de estímulo aos alunos frente ao perfil exigido na Engenharia, sendo muito importante também a Educação Empreendedora, pois tais formas de ensino propõem estímulo à inovação e à proatividade, estabelecendo o aluno como peça principal do processo de aprendizagem. Sendo assim, faz-se necessário a utilização de tais métodos de ensino para a formação profissional nos cursos de Engenharia.

Como pode-se observar no estudo de caso, as metodologias ativas de ensino como TBL, sala de aula invertida e gameficação associadas a avaliação formativa e continuada foram aplicadas e obtiveram resultados positivos, em que os alunos colocaram em prática os conhecimentos adquiridos, sabendo onde procurar informações para manterem seus conhecimentos atualizados. Além da formação de profissionais proativos, inovadores e empreendedores, assim como demandado. Os egressos estarão mais preparados para o mercado de trabalho, já que é possível observar a volatilidade e a necessidade permanente de atualização dos conhecimentos adquiridos, principalmente os tecnológicos. Portanto, não apenas os alunos se beneficiam com estes métodos, também as empresas e o país como um todo, através de profissionais habilidosos, competentes e atualizados.

\section{REFERÊNCIAS}

ABMES. Resolução no 2, de 24 de abril de 2019. ABMES- Associação Brasileira Mantenedoras de Ensino Superior.

ALVES, Lynn Rosalina Gama; MINHO, Marcelle Rose da Silva; DINIZ, Marcelo Vera Cruz. Gamificação: diálogos com a educação. 2014.

AZEVEDO, Sandson Barbosa; PACHECO, Veruska Albuquerque; SANTOS, Elen Alves dos. Metodologias ativas no ensino superior: percepção de docentes em uma 
instituição privada do Distrito Federal. Revista Docência do Ensino Superior, Belo Horizonte, v. 9, e002573, p. 1-22, 2019.

BARBOSA, Eduardo Fernandes; DE MOURA, Dácio Guimarães. Metodologias ativas de aprendizagem na educação profissional e tecnológica. Boletim Técnico do Senac, v. 39, n. 2, p. 48-67, 2013.

BARROS, Emerson Miguel Souza; CARVALHO, Giovanna de; COSTA, Matheus Santana da; SILVA, Mônica Mara da. Metodologias ativas no ensino superior. In: XV Simpósio de Engenharia em Gestão e Tecnologia, 2018.

BERBEL, Neusi Aparecida Navas. As metodologias ativas e a promoção da autonomia de estudantes. Semina: Ciências Sociais e Humanas, v. 32, n. 1, p. 25-40, 2011.

BORGES, Tiago Silva; ALENCAR, Gidélia. Metodologias ativas na promoção da formação crítica do estudante: o uso das metodologias ativas como recurso didático na formação crítica do estudante do ensino superior. Cairu em revista, v. 3, n. 4, p. 119-143, 2014.

DE GUIMARÃES, Julio Cesar Ferro et al. Formação docente: uso de metodologias ativas como processo inovador de aprendizagem para o ensino superior. In: XVI Mostra de Iniciação Científica, Pós-graduação, Pesquisa e Extensão. 2016.

DIESEL, Aline; BALDEZ, Alda Leila Santos; MARTINS, Silvana Neumann. Os princípios das metodologias ativas de ensino: uma abordagem teórica. Revista Thema, v. 14, n. 1, p. 268-288, 2017.

DIESEL, Aline. Protagonismo, educação empreendedora e metodologias ativas de ensino nas licenciaturas: um estudo de caso. Voces y silencios. Revista Latinoamericana de Educación, v. 10, n. 2, p. 32-49, 2019.

DOS SANTOS SILVA, Douglas; ANDRADE, Leane Amaral Paz; DOS SANTOS, Silvana Maria Pantoja. Alternativas de ensino em tempo de pandemia. Research, Society and Development, v. 9, n. 9, p. e424997177-e424997177, 2020.

FARDO, Marcelo Luis. A gamificação aplicada em ambientes de aprendizagem. RENOTERevista Novas Tecnologias na Educação, v. 11, n. 1, 2013.

FARDO, Marcelo Luís. A gamificação como estratégia pedagógica: estudo de elementos dos games aplicados em processos de ensino e aprendizagem. 2013. Tese (Mestrado) Programa de Pós-Graduação em Educação, Universidade de Caxias do Sul, Caxias do Sul, 2013.

GONÇALVES, Lindomar Matias; DE OLIVEIRA, Alexandre Melo; FERREIRA, André Guimarães. O uso de metodologias ativas no ensino para estudantes de engenharia em uma universidade pública, em tempos de atividades remotas. Research, Society and Development, v. 9, n. 10, p. e8819109131-e8819109131, 2020.

HARTZ, Ani Mari; SCHLATTER, Gabriel Vianna. A CONSTRUÇÃO DO TRABALHO DE CONCLUSÃO DO CURSO POR MEIO DA METODOLOGIA ATIVA TEAM-BASED LEARNING/DEVELOPING FINAL COURSE MONOGRAPHS USING A TEAM-BASED LEARNING METHODOLOGY. Administração: Ensino e Pesquisa, v. 17, n. 1, p. 73, 2016.

JUNIOR, Antonio de Araujo Freitas.

JÚNIOR, João Benjamim Cruz, et al. Empreendedorismo e Educação Empreendedora: Confrontação entre Teoria e Prática. Revista de Ciências da Administração - v.8, n.15, jan/jun 2006.

KRUG, Rodrigo de Rosso et al. O "bê-á-bá" da aprendizagem baseada em equipe. Revista Brasileira de Educação Médica, v. 40, n. 4, p. 602-610, 2016.

MARQUES, Ana Paula Ambrósio Zanelato et al. A experiência da aplicação da metodologia ativa Team Based Learning aliada à tecnologia no processo de ensino e de aprendizagem. 2019. Tese (Mestrado) - Faculdade de Educação, Universidade do Oeste Paulista, Presidente Prudente, 2019. 
MORÁN, José. Mudando a educação com metodologias ativas. Coleção mídias contemporâneas. Convergências midiáticas, educação e cidadania: aproximações jovens, v. 2, n. 1, p. 15-33, 2015.

MOREIRA, Maria Eduarda Souza et al. Metodologias e tecnologias para educação em tempos de pandemia COVID-19/Methodologies and technologies for education in times of pandemic COVID-19. Brazilian Journal of Health Review, v. 3, n. 3, p. 6281-6290, 2020. OLIVEIRA, Bruno Luciano Carneiro Alves de et al. Team-based learning como forma de aprendizagem colaborativa e sala de aula invertida com centralidade nos estudantes no processo ensino-aprendizagem. Revista brasileira de educação médica, v. 42, n. 4, p. 86-95, 2018.

OLIVEIRA, Jussara de Fátima Alves Campos et al. Educação no contexto da pandemia da Covid-19. Itinerarius Reflectionis, v. 16, n. 1, p. 01-17, 2020.

RÊGO, Maria Carmem Freire Diogenes; GARCIA, Tulia Fernanda; GARCIA, Tania Cristina, Meira. Ensino Remoto Emergencial estratégias de aprendizagem com Metodologias Ativas. Caderno de Ensino mediado por TIC, 2020.

RIBEIRO, Ricardo de Lima. OLIVEIRA, Edson Aparecida de Araújo Querido. ARAÚJO, Elvira Aparecida Simões de. A contribuição das instituições de ensino superior para a educação empreendedora. G\&DR • v.10, n.3(número especial), p. 295-313 set/2014, Taubaté, SP, Brasil.

SANT ANNA, Antônio Genilton. PATRUS, Roberto. Educação Empresa Em Engenharia: Esse Negócio Requer um Plano. AE - Revista Ensino e Pesquisa em Administração e Engenharia Volume 6, número 1-2020.

SCHAEFER, Ricardo, MINELLO, Italo Fernando, EDUCAÇÃO EMPREENDEDORA: PREMISSAS, OBJETIVOS E METODOLOGIAS. Revista Pensamento Contemporâneo em Administração [Internet]. 2016; 10 (3): 60-81.

SCHERER, Adriana Paula Zamin. O USO DA METODOLOGIA TEAM BASED LEARNING COMO ESTRATÉGIA PARA REVISÃO DE CONTEÚDOS UTILIZANDO O SOFTWARE TBLActive. Pensar Acadêmico, v. 18, n. 4, p. 796-810, 2020.

SCHNEIDERS, Luís A. O método da sala de aula invertida (flipped classroom). Lajeado: ed. da UNIVATES, 2018.

TAVARES, Carlos Eduardo Moreira. MOURA, GL de. ALVES, Juliano Nunes. Educação empreendedora e a geração de novos negócios. Observatorio de la Economía Latinoamericana, n. 188, p. 1-8, 2013.

TREVELIN, Ana Teresa Colenci; PEREIRA, Marco Antonio Alves; DE OLIVEIRA NETO, José Dutra. A utilização da "sala de aula invertida" em cursos superiores de tecnologia: comparação entre o modelo tradicional e o modelo invertido "flipped classroom" adaptado aos estilos de aprendizagem. Revista de estilos de aprendizaje, v. 6, n. 12, 2013.

VALENTE, José Armando. Blended learning e as mudanças no ensino superior: a proposta da sala de aula invertida. Educar em revista, n. 4, p. 79-97, 2014.

Abstract: In order to comprehend the effects caused by the active learning and entrepreneurial education as innovative methods used in some course subjects of Production Engineering at Universidade Federal Fluminense located in Petropolis. It's been analyzed the student's performance and profile after the completion of the following subjects. Therefore, there was a direct influence when it is noticed the increase in performance in the course subjects, ability to seek information, entrepreneurial spirit and greater interest in technology and innovation.

Keywords: Education, Active learning, Innovation, Technology, Students. 